\title{
Shear Wave Velocity Structure Construction Using Ambient Seismic Noise Tomography (ANT) In Palu, Central Sulawesi
}

\author{
Konstruksi Struktur Kecepatan Gelombang S Menggunakan Ambient Seismic Noise Tomography
}

(ANT) Di Palu, Sulawesi Tengah

\author{
Ikhsan, F. A. W. ${ }^{1}$ dan Yudistira, T. ${ }^{2}$ \\ ${ }^{1}$ Teknik Geofisika, Fakultas Teknik Pertambangan dan Perminyakan, Institut Teknologi Bandung, \\ Jalan Ganesa No 10, Bandung, 40132 \\ ${ }^{2}$ Kelompok Keilmuan Geofisika Global, Fakultas Teknik Pertambangan dan Perminyakan, Institut Teknologi Bandung, \\ Jalan Ganesa No 10, Bandung, 40132 \\ *Email:
}

Submit: 15 April 2019; Revised: 10 Juni 2019; Accepted: 15 Agustus 2019

\begin{abstract}
Palu is located in Central Sulawesi, Indonesia, characterized by a complex geological setting due to the intersection of Indo-Australia Plate, Philippine Plate, and Eurasia Plate. These plates intersection causes one of the most active fault systems in Indonesia with $42 \mathrm{~mm} /$ year relative block motion, the Palu-Koro Fault. Palu-Koro Fault system is a left-lateral fault causing the $7.5 \mathrm{Mw}$ Palu-Donggala Earthquake on 28 September 2018. Moreover, the thickness of the sediment layer in Palu amplified the groud motion. So, it is critical to understand more about the Palu-Koro Fault and its geological system that can be very important for hazard study. In this study, Ambient Seismic Noise Tomography (ANT) was applied to understand the Palu-Koro Fault and its geological system. ANT uses the recorded ambient seismic noise events to obtain experimental Greens function by cross-correlating two seismic record data from two seismic station. Technically, ANT is similar to surface wave tomography which produces two dimensional velocity maps. To produce the two dimensional velocity maps, processing sequence consists of the preparation of single station data, stacking, cross-correlation, Frequency-Time Analysis (FTAN), and surface wave tomography. In this study, the vertical component seismic data was processed from 22 stations in Palu to extract the Rayleigh wave dispersion. The entire data was processed at 0,5 - 5 s period range. In addition, depth inversion step was also applied to get the geological features for the further interpretation. The results of this study are the interstation dispersion curves which indicate the group velocity varies between 0.2 and $2 \mathrm{Km} / \mathrm{s}$, the group velocity maps and the shear wave velocity structure at 0,5 5 $K m$ depth. These results show us the existence of the lowvelocity anomaly in the northern part of Palu associated with the coastal sediment, the high-velocity anomaly in the west alongside the $N$-S direction fault, the low-velocity anomaly in the southern eastern part, and three main geological features in Palu based on the East West cross-section. These results lead to an insight that the heavy damage of the Palu-
\end{abstract}

Donggala Earthquake in 2018 was caused by the thickness of the sediment in Palu.

Keywords: Ambient Seismic Noise Tomography, crosscorrelation, Greens function, Frequency-Time Analysis, group velocity, Palu, shear wave velocity structure

Abstrak: Terletak di Sulawesi Tengah, Indonesia, Palu memiliki kondisi geologi yang kompleks. Sesar Palu-Koro merupakan salah satu implikasi dari kompleksitas geologi di Palu. Sesar Palu-Koro adalah sesar mengiri yang menyebabkan Gempa Palu-Donggala 7,5 Mw pada 28 September 2018. Diperkirakan, tebalnya lapisan sedimen di Palu menyebabkan amplifikasi getaran tanah. Dengan demikian, mempelajari Sesar Palu-Koro dan kondisi geologinya merupakan hal yang sangat penting, terutama berkaitan dengan kebencanaan. Dalam penelitian ini, Ambient Seismic Noise Tomography (ANT) digunakan untuk mempelajari Sesar Palu-Koro dan kondisi geologinya. ANT menggunakan rekaman ambient seismic noise untuk memperoleh Greens function eksperimental dengan mengorelasi silangkan dua rekaman seismik dari dua stasiun. Secara teknis, urutan pemrosesan terdiri dari persiapan data tunggal, stacking, korelasi silang, Frequency-Time Analysis (FTAN), tomografi gelombang permukaan, dan inversi kedalaman. Dalam penelitian ini, data seismik komponen vertikal diproses dari 22 stasiun di Palu untuk mengekstrak sifat dispersif gelombang Rayleigh. Seluruh data diproses pada rentang periode 0,5 $5 \mathrm{~s}$. Selain itu, inversi kedalaman juga dilakukan untuk mendapatkan fitur geologi yang kemudian dapat diinterpretasi. Hasil dari penelitian ini adalah kumpulan kurva dispersi yang menunjukkan variasi kecepatan grup antara 0,2 dan 2 $\mathrm{Km}$ / s, peta kecepatan grup, dan struktur kecepatan gelombang S pada kedalaman 0,5 - $5 \mathrm{Km}$. Hasil ini menunjukkan adanya sedimen tebal di bagian utara Palu yang berkaitan dengan sedimen pantai serta anomali kecepatan tinggi di bagian barat yang bersebelahan dengan sesar berarah utara selatan, anomali kecepatan rendah di bagian selatan timur, dan 3 fitur geologi utama di Palu berdasarkan pe- 
nampang cross-section berarah barat - timur. Berdasarkan hasil hasil tersebut, kemungkinan, besarnya dampak gempa Palu-Donggala yang terjadi pada tahun 2018 diakibatkan tebalnya sedimen di Palu.

Kata kunci: Ambient noise tomography, Greens function, Frequency-Time Analysis, kecepatan grup, korelasi silang, Palu, struktur kecepatan gelombang $\mathrm{S}$

\section{PENDAHULUAN}

Kota Palu yang terletak di Sulawesi Tengah memiliki kondisi geologi yang cukup kompleks. Menurut Sopaheluwakan dkk. (1995) stratigrafi Kota Palu dikarakterisasi oleh 3 satuan batuan utama, yaitu Late Miocene Granitoids di bagian paling bawah yang mengintrusi satuan di atasnya, yaitu basement berupa batuan metamorf yang disebut Palu Metamorphic Complex (PMC). Di atas basement tersebut, terdapat lapisan sedimen tebal berumur Mio- pliosen. Selain itu, Kota Palu terletak di sebuah zona sesar bernama Sesar Palu-Koro. Sesar tersebut merupakan sesar geser mengiri yang memiliki komponen menurun.

Thein dkk. (2014) melakukan sebuah penelitian yang memberikan informasi mengenai ketebalan sedimen di Kota Palu. Berdasarkan hasil penelitian tersebut, sedimen di Kota Palu memiliki ketebalan mencapai 25125 meter. Bagian utara merupakan bagian yang memiliki ketebalan paling tinggi. Untuk memahami lebih jauh mengenai kondisi geologi Kota Palu, penelitian ini menggunakan metode $A m b i$ ent Seismic Noise Tomography (ANT). Metode ANT merupakan metode yang memanfaatkan interferometri seismik, yaitu suatu prinsip membangkitkan respon seismik baru yang berasal dari sumber virtual dengan melakukan korelasi silang antar rekaman sinyal seismik pada beberapa lokasi receiver berbeda (Wapenaar dkk., 2010).

Tahapan pengolahan data ambient noise dikemukakan oleh Bensen dkk. (2007) yang meliputi persiapan data tunggal, korelasi silang dan stacking, penentuan kurva dispersi, dan tahap quality control. Pada penelitian ini, setelah didapatkan kurva dispersi antarstasiun, kemudian dilakukan proses tomografi gelombang permukaan pada beberapa periode yang kemudian dilanjutkan dengan tahapan inversi kedalaman.

\section{DATA DAN METODE}

Data yang digunakan dalam penelitian ini adalah data rekaman seismometer tiga komponen dari 22 stasiun perekam yang tersebar di Kota Palu (Gambar 1). Rekaman ini merupakan rekaman selama sekitar tiga bulan pada bulan Februari Mei 2015. Data yang digunakan adalah data yang berasal dari komponen vertikal seismometer (komponen Z), dengan tujuan untuk mendapatkan gelombang Rayleigh. Pada penelitian ini, metode yang digunakan adalah metode Ambient Seismic Noise Tomography (ANT). Pengolahan data dilakukan menggunakan beberapa program yang dikembangkan oleh Yao dkk. (2006), Yudistira dkk. (2017), Farduwin (Komunikasi personal, Mei 2019). Proses pengolahan data ini meliputi persiapan data tunggal, stacking, korelasi silang, frequency-time analysis (FTAN), tomografi gelombang permukaan, dan inversi kedalaman.

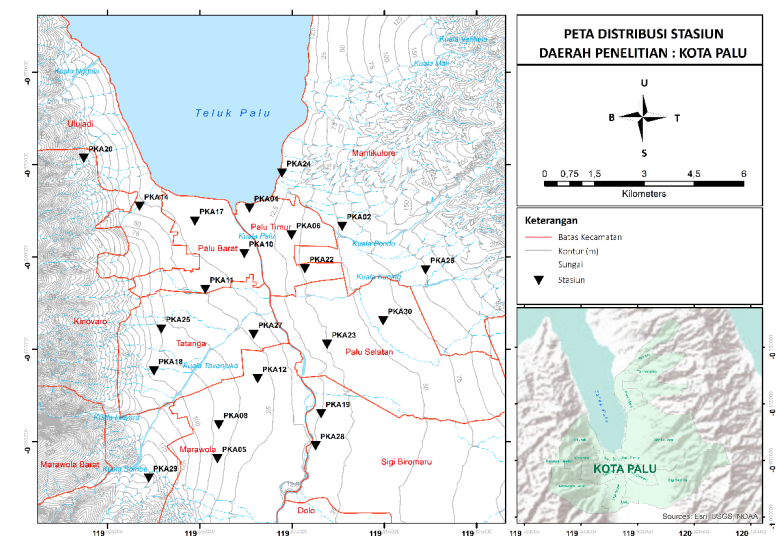

Gambar 1. Peta distribusi stasiun seismik di Palu dan sekitarnya, segitiga hitam terbalik menandakan posisi stasiun seismik.

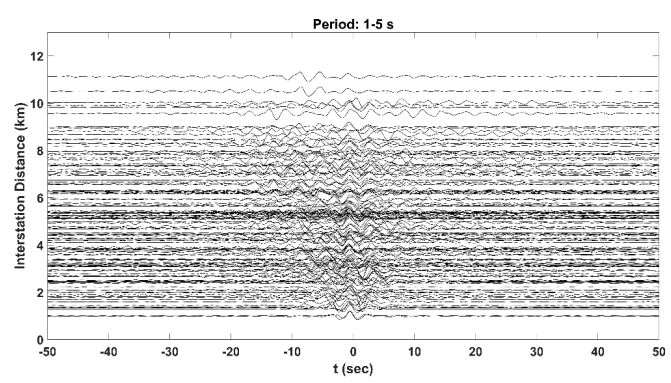

Gambar 2. Waveorm korelasi silang antara salah satu stasiun dengan stasiun lainnya pada periode 1-5 sekon.

Dalam tahapan persiapan data tunggal, setiap rekaman seismik dilakukan demeaning, detrending, spectral whitening, dan filtering pada rentang periode $0.56 \mathrm{~s}$ dengan normalisasi yang digunakan adalah normalisasi one-bit normalization. stacking dilakukan terlebih dahulu pada setiap stasiun secara harian sesuai dengan ketersediaan data. Korelasi silang kemudian dilakukan dengan arah utara selatan dan menghasilkan sebanyak 212 cross- correlation function (CCF). Kumpulan CCF tersebut kemudian dilakukan plotting dalam sebuah grafik yang biasa disebut cross- correlation gather (CCG) untuk melihat gradien pada tiap tiap periode (Gambar 2).

Selanjutnya, untuk menganalisis sifat dispersif yang dimiliki oleh CCF, digunakan metode FTAN. Parameter yang diatur adalah rentang periode antara $0.55 \mathrm{~s}$, spasi 0.01 $\mathrm{s}$, time domain filter berperiode tengah $2.5 \mathrm{~s}$, dan lebar pita 0.1 s. Picking kurva dispersi dilakukan untuk sinyal yang memiliki SNR lebih dari lima dan jarak antarstasiun minimal satu kali panjang gelombang (Gambar 3).

Kurva kurva dispersi antar stasiun kemudian digunakan untuk dilakukan tomografi gelombang permukaan untuk mendapatkan peta kecepatan grup gelombang Rayleigh pada periode $0.5 \mathrm{~s}, 1 \mathrm{~s}, 1.5 \mathrm{~s}, 2 \mathrm{~s}, 2.5 \mathrm{~s}, 3 \mathrm{~s}, 3.5 \mathrm{~s}, 4 \mathrm{~s}, 4.5 \mathrm{~s}$, dan $5 \mathrm{~s}$. Metode inversi tomografi yang digunakan adalah inversi linear. Parameter yang diatur adalah jumlah grid sebanyak $8 \times 8$ buah, parameter regularisasi smoothing dan damping sebesar 6 berdasarkan analisis kurva trade-off, model refer- 


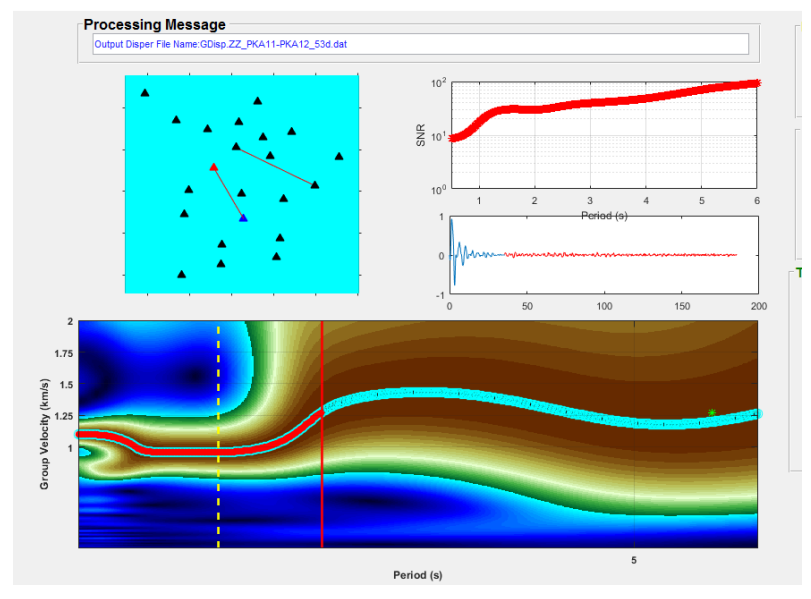

Gambar 3. Hasil picking kurva disperse pada pasangan stasiun PKA11-PKA12.

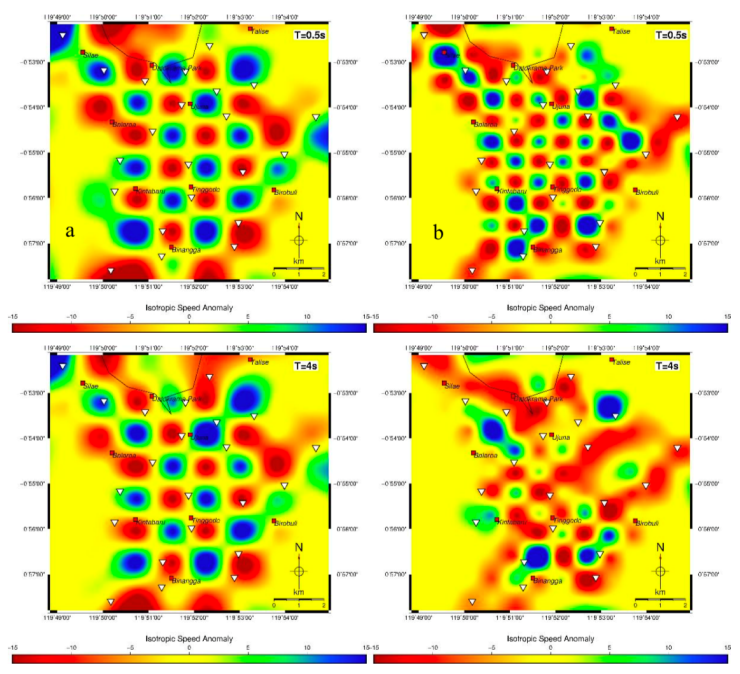

Gambar 4. checkerboard test pada periode 0,5 dan 4 dengan menggunakan grid $8 \times 8$ (a) dan 12x12 (b).

ensi berdasarkan kecepatan rata rata kurva dispersi pada tiap periode, dan digunakan remove outlier dengan threshold sebesar 10. Selain itu, dilakukan analisis checkerboard test sebagai uji resolusi dan didapatkanlah 24 grid yang memiliki resolusi baik (Gambar 4).

Setelah didapatkan peta kecepatan grup pada setiap periode, kemudian dilakukan inversi kedalaman menggunakan metode particle swarm optimization (PSO). Pada prosesnya, inversi kedalaman ini dilakukan pada 24 grid yang beresolusi baik. Pada setiap grid tersebut, metode PSO diterapkan untuk mendapatkan 11 parameter model berupa 6 model kecepatan lapisan dan 5 model ketebalan lapisan. Pencarian kecepatan lapisan dilakukan pada rentang $0.22 \mathrm{Km} / \mathrm{s}$. Sedangkan penentuan tebal lapisan dilakukan pada rentang $0.50 .75 \mathrm{Km}$ pada lapisan pertama dan $0.5 \quad 1.75 \mathrm{Km}$ untuk lapisan lapisan berikutnya.

\section{HASIL DAN PEMBAHASAN}

Hasil yang diperoleh dari penelitian ini berupa CCF, CCG, kurva dispersi antarstasiun, peta kecepatan grup dua dimensi yang bervariasi berdasarkan periode, dan struktur kecepatan gelombang S. Hasil - hasil tersebut kemudian dilakukan analisis untuk mengetahui kondisi geologi Kota Palu secara umum. Berdasarkan CCF, dapat dilihat karakter dispersif gelombang permukaan.

Berdasarkan CCG, kembali dapat dilihat karakter dispersif yang ditunjukkan dengan adanya perbedaan gradien bentuk V pada setiap rentang periode. Selain itu, bentuk V dapat digunakan untuk memperkirakan kecepatan di daerah tersebut secara umum. Berdasarkan analisis tersebut, didapatlan kecepatan di Kota Palu bervariasi antara $0.2 \quad 1.5$ $\mathrm{Km} / \mathrm{s}$.

Kurva - kurva dispersi antarstasiun yang dihasilkan dari tahapan FTAN kemudian dikumpulkan dalam suatu grafik. Grafik tersebut menunjukkan adanya variasi kecepatan grup pada tiap tiap periode yang bervariasi antara $0.22 \mathrm{Km} / \mathrm{s}$. Variasi kecepatan ini kemudian dijadikan rentang pencarian pada proses inversi kedalaman.

Peta kecepatan grup digunakan sebagai analisis awal terhadap kondisi geologi Kota Palu. Berdasarkan peta kecepatan grup yang dihasilkan, dapat dilihat adanya anomali anomali kecepatan grup yang berbeda pada beberapa bagian. Pada bagian utara, terdapat anomali kecepatan rendah sekitar $-5 \%$. Sedangkan di bagian barat - tengah, terdapat anomali kecepatan tinggi sekitar $+15 \%$. Pada bagian selatan timur, terdapat anomali kecepatan rendah sekitar -7\%. Gambar 9 menunjukkan peta kecepatan grup pada periode $0.5 \mathrm{~s}$ dan $1 \mathrm{~s}$.

Struktur kecepatan gelombang S di Kota Palu yang seperti ditunjukkan pada Gambar 6, sebagian besar berkorelasi dengan peta kecepatan grupnya. Struktur kecepatan gelombang $\mathrm{S}$ ini digunakan untuk menganalisis kondisi geologi Kota Palu. Berdasarkan struktur kecepatan gelombang $\mathrm{S}$ pada kedalaman $0.51 \mathrm{Km}$, dapat dilihat adanya anomali kecepatan rendah (-7\%) di bagian utara yang diinterpretasi merupakan akibat dari adanya endapan pantai di daerah tersebut. Anomali kecepatan tinggi $(+15 \%)$ kembali tampak seperti pada peta kecepatan grup, hal ini diperkirakan berasosiasi dengan batuan relatif keras yang menghasilkan topografi berupa tinggian di daerah tersebut. Pada bagian selatan timur, anomali kecepatan rendah (-10\%) diperkirakan berasosiasi dengan adanya sedimen tebal di daerah tersebut.

Selain itu, berdasarkan struktur kecepatan gelombang $\mathrm{S}$ pada kedalaman $0.51 \mathrm{Km}$, diperkirakan terdapat sesar berarah utara selatan yang ditunjukkan oleh adanya kontras antara kecepatan tinggi dan rendah di bagian selatan. Meskipun demikian, keberadaan kontras kecepatan tersebut hanya tampak pada bagian selatan Kota Palu.

\section{KESIMPULAN}

Peta kecepatan grup tersebut menunjukkan adanya anomali kecepatan rendah (-5\% dan $-7 \%$ ) di bagian utara dan selatan timur serta anomali kecepatan tinggi (+15\%) di bagian barat Kota Palu. Struktur kecepatan gelombang $\mathrm{S}$ dapat digunakan untuk mengetahui kondisi geologi Kota 


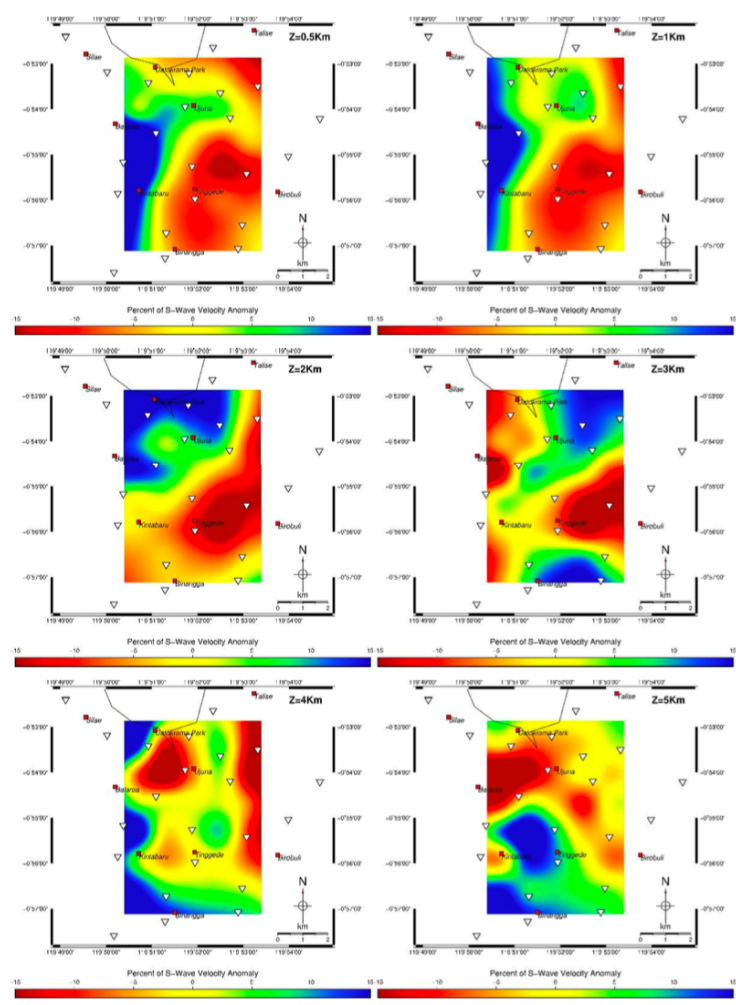

Gambar 5. Peta struktur kecepatan gelombang S pada kedalaman $0.55 \mathrm{~km}$, segitiga terbalik menggambarkan lokasi stasiun seismik.

Palu secara umum dan sebagian besar bersesuaian dengan peta kecepatan grup dengan beberapa pengecualian yang diakibatkan karakteristik kurva kecepatan grup. Struktur kecepatan gelombang $\mathrm{S}$ menunjukkan adanya anomali kecepatan rendah $(-7 \%$ dan $-10 \%)$ di bagian utara dan selatan timur serta anomali kecepatan tinggi $(+15 \%)$ di bagian barat Kota Palu. Kondisi geologi daerah Palu bagian utara berasosiasi dengan endapan pantai. Di bagian barat, kondisi geologi berasosiasi dengan batuan relatif keras yang memiliki kecepatan gelombang S tinggi. Sedangkan di bagian selatan timur terdapat sedimen yang cukup tebal. Secara keseluruhan, daerah Palu terdiri dari tiga satuan batuan, yaitu batuan sedimen kuarter, Palu Metamorphic Complex (PMC), dan batuan granitoid berumur pliosen akhir. Keberadaan sedimen yang cukup tebal memberikan kontribusi terhadap besarnya dampak gempa yang terjadi pada tahun 2018. Secara umum, interpretasi yang didasarkan oleh distribusi kecepatan gelombang $\mathrm{S}$ dari hasil rekaman seismic noise ini bersesuaian dengan hasil penelitian beberapa peneliti sebelumnya, sehingga saling menunjang dalam memahami kondisi bawah permukaan kota Palu.

\section{DAFTAR PUSTAKA}

Sopaheluwakan, J., Kadarusman, A., Priadi, B., dan Utoyo, H. (1995). The nature of basement rocks in Palu region, Central Sulawesi. The Newly found eclogite and its regional implication. Proceedings of Sixth International
Congress on Pacific Neogene Stratigraphy and IGCP, 355, 7339.

Thein, P. S., Pramumijoyo, S., Brotopuspito, K. S., Kiyono, J., Wilopo, W., Furukawa, A., dan Setianto, A. (2014). Estimation of Seismic Ground Motion and Shaking Parameters Based On Microtremor Measurements at Palu City, Central Sulawesi Province, Indonesia. International Journal of Geological and Environmental Engineering, 8, 308-319.

Wapenaar, K., Draganov, D., Snieder R., Campman, X., dan Verdel, A. (2010). Tutorial on seismic interferometry: Part 1 Basic principles and applications. Geophysics, 75, 75A19575A209.

Bensen, G.D., Ritzwoller, M.H., Barmin, M.P., Levshin, A.L., Lin, F., Moschetti, M.P., Shapiro, N.M., dan Yang, Y. (2007). Processing Ambient seismic noise Data to Obtain Reliable Broad- band Surface Wave Dispersion Measurements. Geophys J.Int, 169, 1239-1260.

Yao, H., van der Hilst R.D., dan de Hoop, M.V., (2006). Surface-wave array tomography in SE Tibet from ambient seismic noise and two-station analysis: I - Phase velocity maps. Geophys.J. Int., 166(2), 732-744.

Yudistira, T., Paulssen, H., dan Trampert, J. (2017). The crustal structure beneath The Netherlands derived from ambient seismic noise. Tectonophysics, 721, 361-371. 